Article

\title{
Investigation of X-ray Radiation Detectability Using Fabricated ZnO-PB Based Extended Gate Field-Effect Transistor as X-ray Dosimeters
}

\author{
Amal Mohamed Ahmed Ali ${ }^{1}$, Naser M. Ahmed ${ }^{1}$ * ${ }^{\mathbb{D}}$, Norlaili A. Kabir ${ }^{1}$, Mohammed Khalil Mohammed Ali ${ }^{2}$, \\ Hanan Akhdar ${ }^{2} * \mathbb{D}$, Osamah A. Aldaghri ${ }^{2}$, ${ }^{\text {Khalid Hassan Ibnaouf }}{ }^{2}$ and Abdelmoneim Sulieman ${ }^{3}$ (D) \\ 1 School of Physics, Universiti Sains Malaysia, Seberang Perai 11800, Penang, Malaysia; \\ ammalloooo1@gmail.com (A.M.A.A.); norlailikabir@usm.my (N.A.K.) \\ 2 Physics Department, College of Science, Imam Mohammad Ibn Saud Islamic University (IMSIU), \\ Riyadh 13318, Saudi Arabia; hamofarog@yahoo.com (M.K.M.A.); odaghri@gmail.com (O.A.A.); \\ kheo90@gmail.com (K.H.I.) \\ 3 Medical Imaging Sciences Department, College of Applied Medical Sciences, Prince Sattam Bin Abdulziz \\ University, P.O. Box 422, Alkharj 11942, Saudi Arabia; a.sulieman@psau.edu.sa \\ * Correspondence: nas_tiji@yahoo.com (N.M.A.); hfAkdar@imamu.edu.sa (H.A.)
}

\section{check for}

updates

Citation: Ahmed Ali, A.M.; Ahmed, N.M.; Kabir, N.A.; Ali, M.K.M.;

Akhdar, H.; Aldaghri, O.A.; Ibnaouf, K.H.; Sulieman, A. Investigation of $X$-ray Radiation Detectability Using Fabricated ZnO-PB Based Extended Gate Field-Effect Transistor as X-ray Dosimeters. Appl. Sci. 2021, 11, 11258 https://doi.org/10.3390/ app112311258

Academic Editor: Pedro Costa

Received: 24 October 2021

Accepted: 18 November 2021

Published: 27 November 2021

Publisher's Note: MDPI stays neutral with regard to jurisdictional claims in published maps and institutional affiliations.

Copyright: (c) 2021 by the authors. Licensee MDPI, Basel, Switzerland. This article is an open access article distributed under the terms and conditions of the Creative Commons Attribution (CC BY) license (https:// creativecommons.org/licenses/by/ $4.0 /$ )

\begin{abstract}
A new design of the MOSFET dosimeter is being developed in a different study to measure the dose delivered to the tissue layers. Development of zinc oxide-Lead $(\mathrm{ZnO}-\mathrm{Pb})$ of different thicknesses fabricated by chemical bath deposition were investigated to study their sensitivity following irradiation using a low absorbed dose that can be used in diagnostic and interventional radiology $(9,36.5$, and $70 \mathrm{mGy})$ and high absorbed dose (1, 5, and $10 \mathrm{~Gy})$ of X-ray. The morphology and structure of the as-prepared films were analysed using FESEM and XRD measurements. The device relies on sensing the changes in the local electric field arising from radiation interactions in the absorber, coupled with the semiconductor materials used in this work- $\mathrm{ZnO}-\mathrm{Pb}$ as the EGFET. Then the sensitivity of all devices was examined. Generally, thin-film devices showed less sensitivity to $\mathrm{X}$-ray than the disk type. The sensitivity of the thin film dropped from $6.66 \mathrm{mV} /$ to $1.42 \mathrm{mV} / \mathrm{Gy}$, while the sensitivity of the $\mathrm{ZnO}-\mathrm{Pb}$ disk type was $23.3 \mathrm{mV} / \mathrm{Gy}$, which then dropped to $6.306 .42 \mathrm{mV} / \mathrm{Gy}$. Furthermore, the disk type $\mathrm{ZnO}-\mathrm{Pb}$ was exposed to a high absorbed dose and obtained a sensitivity value of $0.08 \mathrm{mV} / \mathrm{Gy}$, while the $\mathrm{ZnO}-\mathrm{Pb}$ thin film obtained $0.01 \mathrm{mV} / \mathrm{Gy}$. This can be related to the influence of thickness on the sensitivity of the dosimeter. However, the device's performance characteristics, like sensitivity to radiation exposure and operating dose area, were discovered to be strongly dependent on the materials employed, effective atomic number, and thickness of the materials. Based on the results shown above, these devices might be considered a low-cost candidate for real-time -radiation dosimetry at room temperature. Furthermore, the thickest sample of $1 \mathrm{~mm}$ showed better sensitivity to radiation, compared to the thinner samples.
\end{abstract}

Keywords: X-ray; radiation detector; EGFET; MOSFET; gamma ray; personal dosimeter; thin film

\section{Introduction}

Radiation detectors are used in a variety of areas, including health, industry, and science. Ionizing radiation ( $\mathrm{X}$-and $\gamma$-ray) exposure may occur in these settings; therefore, proper radiation detection is critical for protecting the environment. The type of dosimeter used for a given application is determined by the energy range. Metal oxides are a well-known kind of substance utilized in dosimetry. It is concerned with the creation of particular structural flaws termed color centers as a result of radiation [1]. Metal oxide semiconductor field effect transistors (MOSFETs) might combine dose data and give an instant dose reading [2]. Because of its insensitivity to environmental conditions such as temperature and light, and even its flexibility extended gate, the extended-gate field-effect transistor (EGFET) structure has garnered greater attention in packaging and 
contact resistance. Furthermore, EGFETs may be utilized without exposing the metal oxide semiconductor field effect transistor (MOSFET) to irradiation, allowing it to be reused several times [3]. The EGFET design allows the MOSFET to be isolated from its biological or chemical surroundings. A sensing membrane is connected to the end of a signal line, which is connected to the MOSFET. Furthermore, by allowing the use of larger samples without being limited by the size of the MOSFET, this design gives a wider detection area [4]. Ionizing radiation dosimetry with irradiation sensor MOSFETs is dependent on translating the threshold voltage shift $\mathrm{V}_{\mathrm{TH}}$ into the absorbed dose $\mathrm{D}$. This transition is caused by radiation-induced electron-hole pairs in the transistor's gate oxide layer, which leads to a rise in the density of interface traps and the accumulation of positive trapped charge. Extended gate field effect transistors (EGFETs) have adjustable sensitivity, rendering them ideal for a wide range of applications. Sensitivity, for example, can be adjusted by varying the thickness of the gate oxide layer [5,6]. Instead, transistors can be stacked in specific circumstances $[7,8]$. The sensitivity could also be adjusted by providing a positive bias to the gate while it is being irradiated [9]. Electric charges are produced and trapped inside the gate oxide layer (Qox,i) or even at the oxide-silicon interface (Qit,i) when a MOSFET is exposed to photons. When Qox, $\mathrm{i}$ is positive, the transfer characteristics $\mathrm{I}_{\mathrm{d}}$ (drain current) against $V_{g}$ (gate voltage) change towards negative voltages. The interface charges Qjt,i mostly contribute to the deterioration of the carriers mobility $\mathrm{p}$ inside the channel, reducing the slope of the linear component of the characteristics [10].

The threshold voltage $\mathrm{V}_{\mathrm{TH}}$ is defined as the point at which the linear component of the curve intersects the $\mathrm{V}_{\mathrm{g}}$ axis and is provided by:

$$
\mathrm{V}_{\mathrm{TH}}=\mathrm{V}_{\mathrm{TH} 0}-\frac{\text { Qox, } \mathrm{i}+\text { Qit, } \mathrm{i}}{\text { Cox }}=\mathrm{V}_{\mathrm{TH} 0}+\Delta \mathrm{V}_{\mathrm{TH}}
$$

where $\mathrm{V}_{\mathrm{TH} 0}$ is the pre-irradiation value of the $\mathrm{V}_{\mathrm{TH}}$ and Cox is the capacitance of the gate. The measurement of the change $\Delta \mathrm{VTH}$ of the threshold voltage after radiation allows the evaluation of the absorbed dose. Whenever the surface potential $\Psi_{\mathrm{S}}$ is equal to Fermi's potential $\Psi_{\mathrm{F}}$ and Fermi's level lies in the center of the semiconductor's energy gap, interface traps are neutral (overall charge equals zero), regardless of the dispersion throughout the semiconductor energy gap. The charge of FT simply causes the shift between two subthreshold properties toward this VG-axis, and the gate voltage that correlates to such surface potentials is designated as $\mathrm{V}_{\mathrm{MG}}$ (midgap voltage) and might even be calculated as the ordinate of the $\left(\mathrm{V}_{\mathrm{MG}}, \mathrm{I}_{\mathrm{MG}}\right)$ point at subthreshold features [11]. The $\mathrm{V}_{\mathrm{MG}}$, i.e., $\mathrm{V}_{\mathrm{G}}$ which correlates to $I_{D}=I_{M G}$, may be determined as $V_{M G}=\left[\log \left(I_{M G}-n\right) / m\right]$ using the formula $\log \left(\mathrm{I}_{\mathrm{D}}\right)=\mathrm{m} \cdot \mathrm{V}_{\mathrm{G}}+\mathrm{n}$ derived by the linear curve of subthreshold characteristic. $\mathrm{V}_{\mathrm{MG} 0}$ and $\mathrm{V}_{\mathrm{MG}}$ are discovered using this method. The straight lines generated by the linear fittings of subthreshold properties are gradually applied to the appropriate midgap current $\mathrm{I}_{\mathrm{MG}}$.

$\Delta \mathrm{V}_{\mathrm{ft}}$ is the factor of threshold voltage changes caused by FT, as:

$$
\Delta \mathrm{V}_{\mathrm{ft}}=\Delta \mathrm{V}_{\mathrm{MG}}=\mathrm{V}_{\mathrm{MG}}-\mathrm{V}_{\mathrm{MG} 0}
$$

where $\mathrm{V}_{\mathrm{MG} 0}$ and $\mathrm{V}_{\mathrm{MG}}$ are the midgap voltages in between irradiation. Vst is the component of threshold voltage shift caused by ST.

$$
\Delta \mathrm{V}_{\mathrm{st}}=\left(\mathrm{V}_{\mathrm{T}}-\mathrm{V}_{\mathrm{MG}}\right)-\left(\mathrm{V}_{\mathrm{T} 0}-\mathrm{V}_{\mathrm{MG} 0}\right)=\mathrm{V}_{\mathrm{S}}-\mathrm{V}_{\mathrm{S} 0}
$$

where $\mathrm{V}_{\mathrm{T} 0}$ and $\mathrm{V}_{\mathrm{T}}$ are the threshold voltages of transistors before and after irradiation, respectively, and threshold voltage shift is $\Delta \mathrm{VT}=\mathrm{V}_{\mathrm{T}}-\mathrm{V}_{\mathrm{T} 0} . \mathrm{V}_{\mathrm{T} 0}$ and $\mathrm{V}_{\mathrm{T}}$ are calculated from the saturation transfer characteristics as the junction of the $\mathrm{V}_{\mathrm{G}}$-axis and the extrapolation linear area of the curves $\sqrt{ }_{\mathrm{D}}=f \mathrm{~V}_{\mathrm{G}}$. [12]. Optical thin films have been the focus of conducting film research. Because of its advantages, such as economic feasibility and nontoxicity, $\mathrm{ZnO}$ thin films have indeed been employed in a variety of applications [13,14]. According to reports, $\mathrm{ZnO}$ has (i) better quantum efficiency, (ii) great photochemical characteristics, and (iii) the capacity to produce a high-quality single crystal at a low 
price [15]. It is also a low-cost luminous and biofriendly oxide semiconductor device. Appropriately, $\mathrm{ZnO}$ is predicted to find widespread use in UV laser, biosensing, bioimaging, drug development, and other fields. Doping substances with $\mathrm{ZnO}$, such as lead $(\mathrm{Pb})$, offers benefits. They discovered that $\mathrm{Pb}$ does have an impact on the size and shape of $\mathrm{ZnO}$ [16]. The inclusion of lead nanoparticles is accountable for the modified electrode's increased sensor activity. The significant improvement might be attributed to the synergistic impact of both $\mathrm{Pb}$ and $\mathrm{ZnO}$ nanoparticles [17]. In this work, $\mathrm{ZnO}-\mathrm{Pb}$ thin and thick film were synthesised via chemical bath deposition (CBD) and their structural and morphological properties investigated. The samples were applied to use as low and high radiation detector-based EGFET.

\section{Materials and Methods}

In total, $2.615 \mathrm{~g}$ of Zinc Nitrate $\left(\mathrm{Zn}\left(\mathrm{NO}_{3}\right)^{2}, 6 \mathrm{H}_{2} \mathrm{O}\right)$ and $1.4 \mathrm{~g}$ of hexamethylenetetramine $\left(\mathrm{C}_{6} \mathrm{H}_{12} \mathrm{~N}_{4}\right)$ were added to $200 \mathrm{~mL}$ deionized water to prepare a solution of $50 \mathrm{mM}$. The solution was then stirred for $1 \mathrm{~h}$ at room temperature. $3.31 \mathrm{~g}$ of Lead (II) Nitrate $\mathrm{Pb}$ $\left(\mathrm{NO}_{3}\right)^{2}$ salt was added to the solution and stirred continuously. A $\mathrm{ZnO}$ seed layer on glass substrates were immersed upside down to the solution, then covered and kept in a chemical bath deposition for $8 \mathrm{~h}$ at $90{ }^{\circ} \mathrm{C}$. The thin film was then removed, washed with deionized water, and dried in air. These steps were repeated three times to increase the thickness of the films. The film thickness was then measured by FESEM, and it was found that the thickness reached $46 \mu \mathrm{m}$. The solution was filtered and dried using an oven at $80^{\circ} \mathrm{C}$ for $15 \mathrm{~min}$, then pressed with a hydraulic press to $1 \mathrm{~mm}$ thickness.

XRD was used to study the structural properties and the particle size for both films was calculated using Scherer's formula, as mentioned in [18]:

$$
\mathrm{d}=\frac{0.89 \lambda}{B \cos \theta \beta}
$$

where $B$ is the crystalline XRD peak's entire width at half maximum, $\theta \beta$ is the Bragg's angle, and $\lambda$ is the $X$-ray wavelength $(0.154 \mathrm{~nm})$. FESEM was also used to study the morphological properties of the samples and then the Energy Dispersive X-ray Spectroscopy (EDX) model was used to determine the fractional weight of each element in a combination. Since the sample is a mixture of elements, effective atomic number $\left(Z_{\text {eff }}\right)$ of the mixture was obtained using Equation (5) [19]:

$$
\text { Zeff }=\sqrt[2.94]{\left(\mathrm{f} 1 Z_{1}^{2.94}+\mathrm{f} 2 Z_{2}^{2.94}+\ldots \ldots \mathrm{fn} Z_{n}^{2.94}\right)}
$$

where, $\mathrm{f}=$ the weight fractions for every component in the medium of interest in relation to the total number of electrons consumed within the compound/mixture that forms the medium. $\mathrm{Z}$ denotes the atomic number of every element included in the medium. The value used for actual practical applications is generally 2.94 [19]. Silver electrodes were deposited as fingerprint interdigitated on the samples, and silver paste was used to connect the wires. The samples were then connected as an extended gate to the MOSFET to study the I-V characterization under a low absorbed dose $(9,36$ and $70 \mathrm{mGy})$ using the X-ray machine at the School of Physics, USM, and high absorbed dose (1, 5 and 10 Gy) using a radiotherapy machine (Elekta) at Gleneagles Hospital, Penang, Malaysia.

MOSFET is connected to the semiconductor thick film through the gate to keep the first device away from radiation. Radiation interacts directly with semiconductors, which leads to changes in their properties, such as increase in the amount of current that reaches the MOSFET. The current increases as the amount of radiation dose increases. The EGFET connection setup is mentioned in [18]. The sensing component ( $\mathrm{ZnO}-\mathrm{Pb})$ and a commercialized MOSFET (CD4007UB) are the two primary components of an EGFET. Figure 1 depicts the $\mathrm{ZnO}-\mathrm{Pb}$-based EGFET $\mathrm{X}$-ray detector. The sensing portion of the sensor was linked to a gate of the MOSFET. The sensing layer was exposed to an X-ray source before being attached to the measuring equipment. The dosimeter's reaction was 
examined using a Keithley 2400 and Lab Tracer 2 software. The connection used in this work is mentioned in [18].

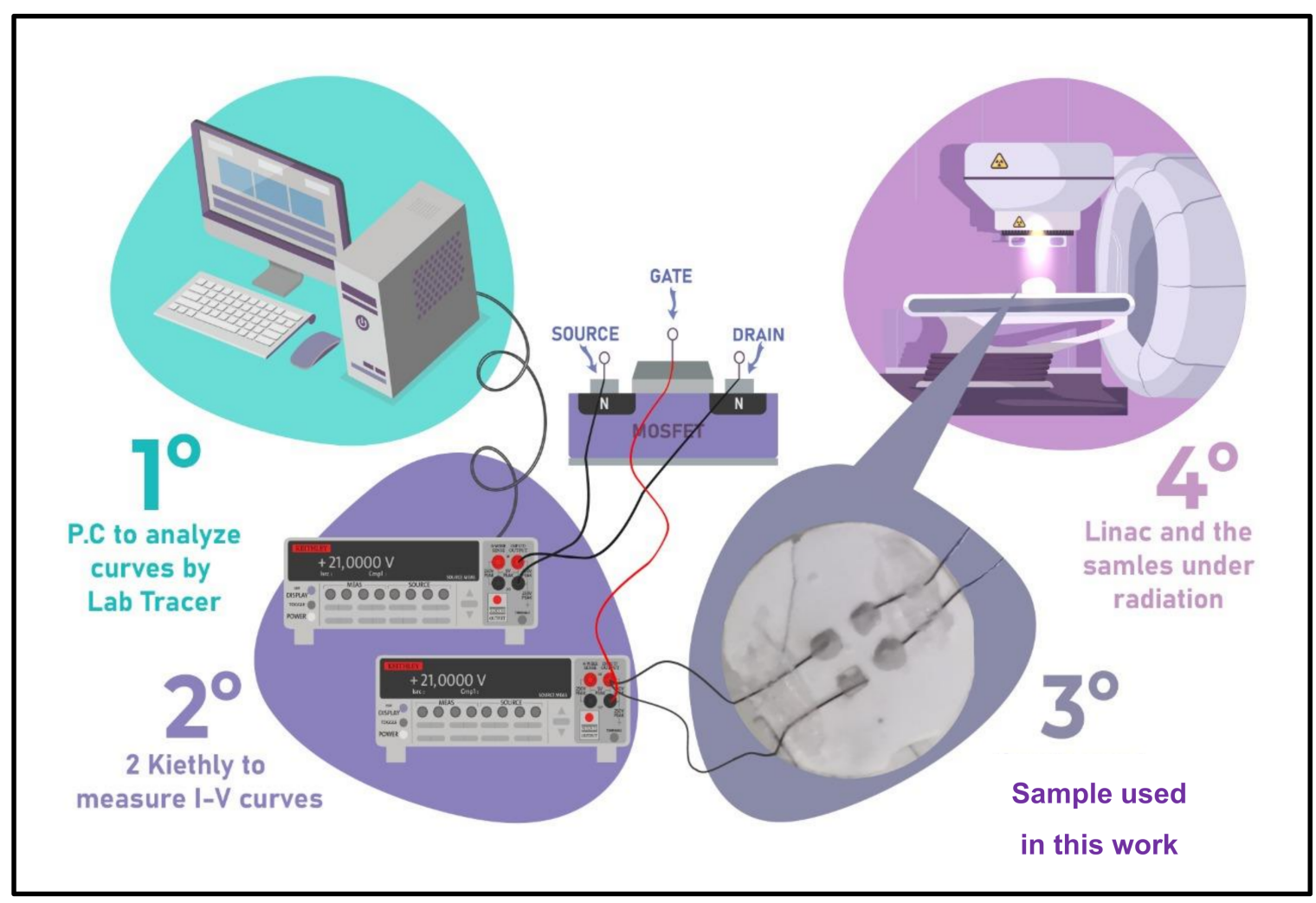

Figure 1. The connection used in this work for EGFET.

The film's sensitivity was measured in terms of the threshold voltage $\left(\mathrm{V}_{\mathrm{TH}}\right)$, which was determined using Equation (1) [20]. The detection sensitivity of the samples to X-ray exposure was determined using the formula below:

$$
S=V_{T H} / D
$$

where $S$ denotes sensitivity and $\mathrm{D}$ indicates the absorbed dose.

\section{Results and Discussion}

Properties of the thin films and disks: Figure 2 shows the FESEM images for the morphology of $\mathrm{ZnO}-\mathrm{Pb}$ thin films deposited on glass substrates and for disks prepared by using CBD. The thin film's morphology consists of hexagonal crystal formations that are perfectly aligned and tightly packed nanorods. This result agrees with a previous work [21]. The fractional atomic percentage of the $\mathrm{ZnO}-\mathrm{Pb}$ thin film was determined by using the (EDX) technique. Figure 2A also shows the EDX results of the $\mathrm{ZnO}-\mathrm{Pb}$ thin film. Figure $2 \mathrm{~B}$ presents that in the FESEM micrographs of the $\mathrm{ZnO}-\mathrm{Pb}$ disk type images, the $\mathrm{ZnO}-\mathrm{Pb}$ grains appeared as a homogeneous nanorod shape. The same figure also shows the fractional atomic percentage of an investigated $\mathrm{ZnO}-\mathrm{Pb}$ disk type obtained via EDX procedures. Equation (5) was used to determine the Zeff of the studied samples, which was found to be 72.5 .

Figure $3 \mathrm{~A}$ represents the crystalline peaks of $\mathrm{ZnO}-\mathrm{Pb}$ for thin films. The diffraction peaks observed at diffraction angles $2 \theta$ of $31.37^{\circ}$ and $36.22^{\circ}$ correspond to (100) and (101) plans of the $\mathrm{ZnO}-\mathrm{Pb}$ thin film. The amorphous nature of the thin film pattern is due to the lack of thin film thickness. On the other hand, Figure 3B shows the diffraction peaks of the disk type powder at angles $2 \theta$ of $31.66^{\circ}, 34.34^{\circ}, 36.16^{\circ}, 47.46^{\circ}, 56.45^{\circ}$, and $62.71^{\circ}$ corresponding to the (100), (002), (101), (102), (110), and (103) plans of $\mathrm{ZnO}-\mathrm{Pb}$ disk, 
respectively. The essential characteristics of the diffraction patterns are identical, but the relative strength of the diffraction peaks rises as the film thickness increases [22]. The average crystal size of the nanostructured $\mathrm{ZnO}-\mathrm{Pb}$, as calculated from the Scherrer formula Equation (4), is shown in Table 1.

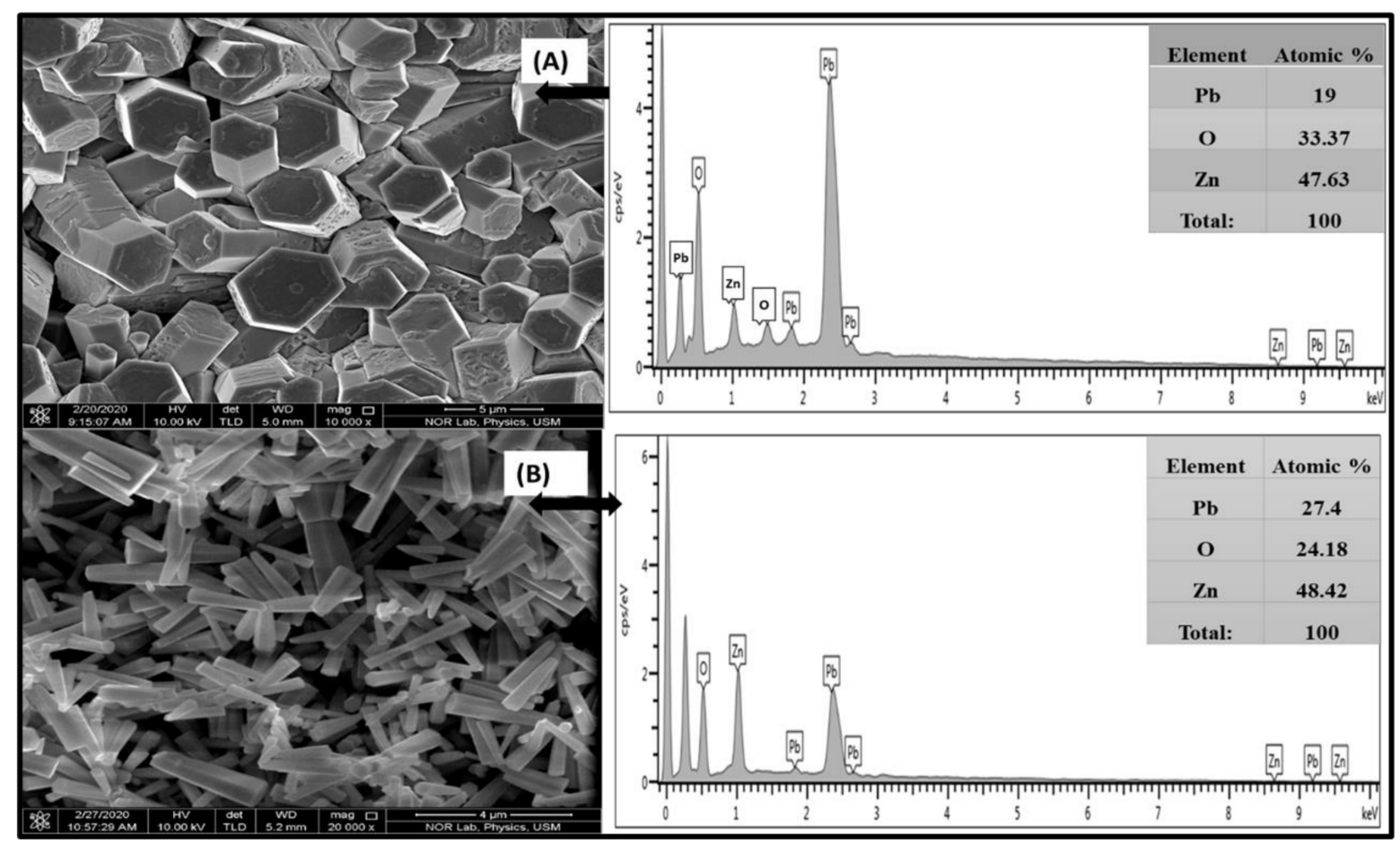

Figure 2. FESEM images of the nanostructured $\mathrm{ZnO}-\mathrm{Pb}(\mathbf{A})$ thin film and (B) powder of the disk, and their EDX.

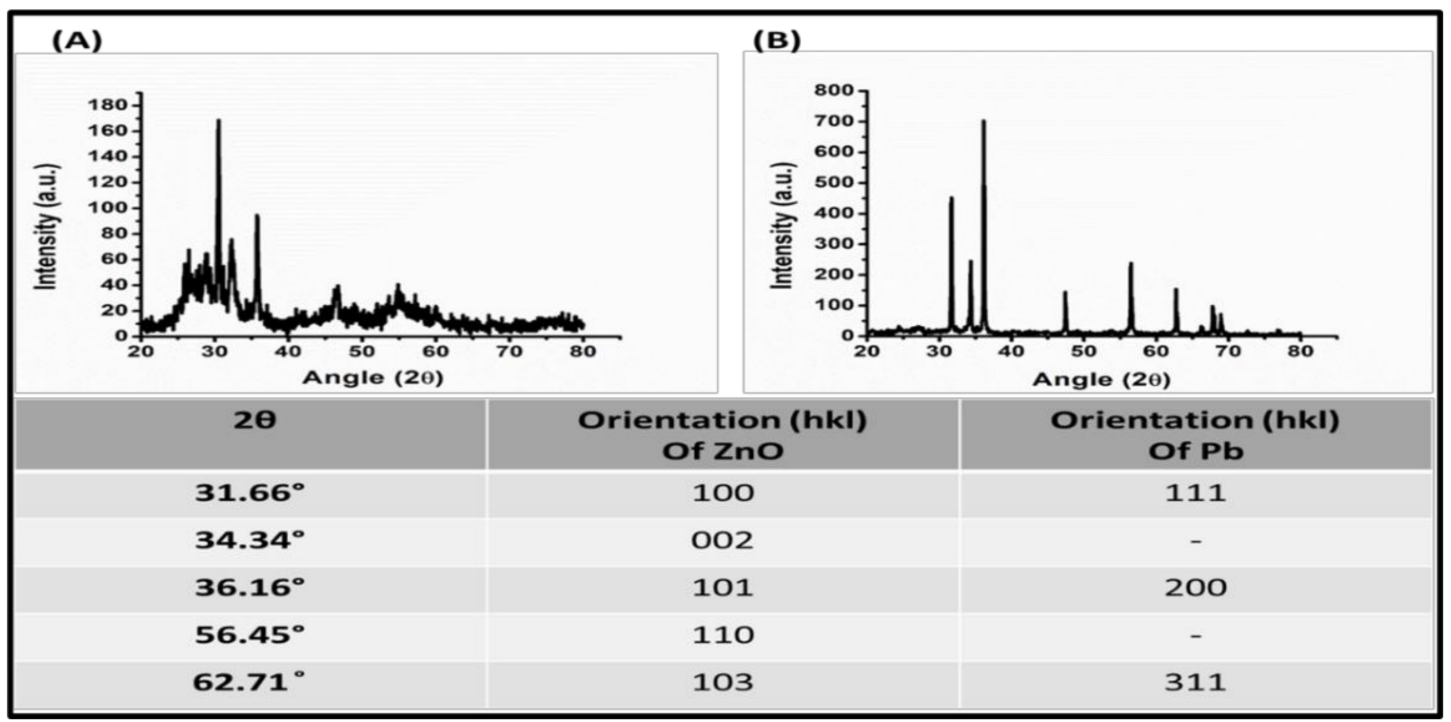

Figure 3. XRD graphs for (A) thin film $\mathrm{ZnO}-\mathrm{Pb}$ and (B) $1 \mathrm{~mm}$ disk $\mathrm{ZnO}-\mathrm{Pb}$.

Table 1. The particles size and (Zeff) for the samples used in the study.

\begin{tabular}{cccc}
\hline Sample & TF Particle Size (nm) & Disk Particle Size (nm) & Effective Atomic Number \\
\hline $\mathrm{ZnO}-\mathrm{Pb}$ & 6.97 & 15.97 & 72.5 \\
\hline
\end{tabular}


As shown in Figure 1, the $\mathrm{ZnO}-\mathrm{Pb}$ thin film (TF) and disk type $(1 \mathrm{~mm})$ were selected as EGFETs and applied as radiation sensors. The radiation sensitivity of the membranes was tested using various radiation doses $(9,36.5$, and $70 \mathrm{mGy})$. As illustrated in Figure $4 \mathrm{~A}, \mathrm{~B}$, the results of these measurements were converted into I-V curves in both linear and saturation regimes $(\mathrm{B})$. The linear regime was reached with a steady drain-to-source voltage $\left(\mathrm{V}_{\mathrm{ds}}\right)$ of $0.3 \mathrm{~V}$ and the saturation regime with a fixed gate-to-source voltage $\left(\mathrm{V}_{\mathrm{gs}}\right)$ of $3 \mathrm{~V}$. The linear regime curves show a shift of the threshold voltage to the left by increasing the absorbed dose, while the saturation regime curves show the current increased by increasing the doses of radiation up to $70 \mathrm{mGy}$ for the low absorbed dose. This increasing of the current in the saturation regime can be due to electron-hole pairs being formed during irradiation, resulting in higher electrical properties such as current [23]. The effect of the absorbed dose led to increment of the current; these modifications are greatly influenced by the internal composition of the ingested chemicals. The interaction process of $\mathrm{X}$-rays with substances is essentially based on electronic excitation, electronic ionization, and atomic movement of outer electrons [24].

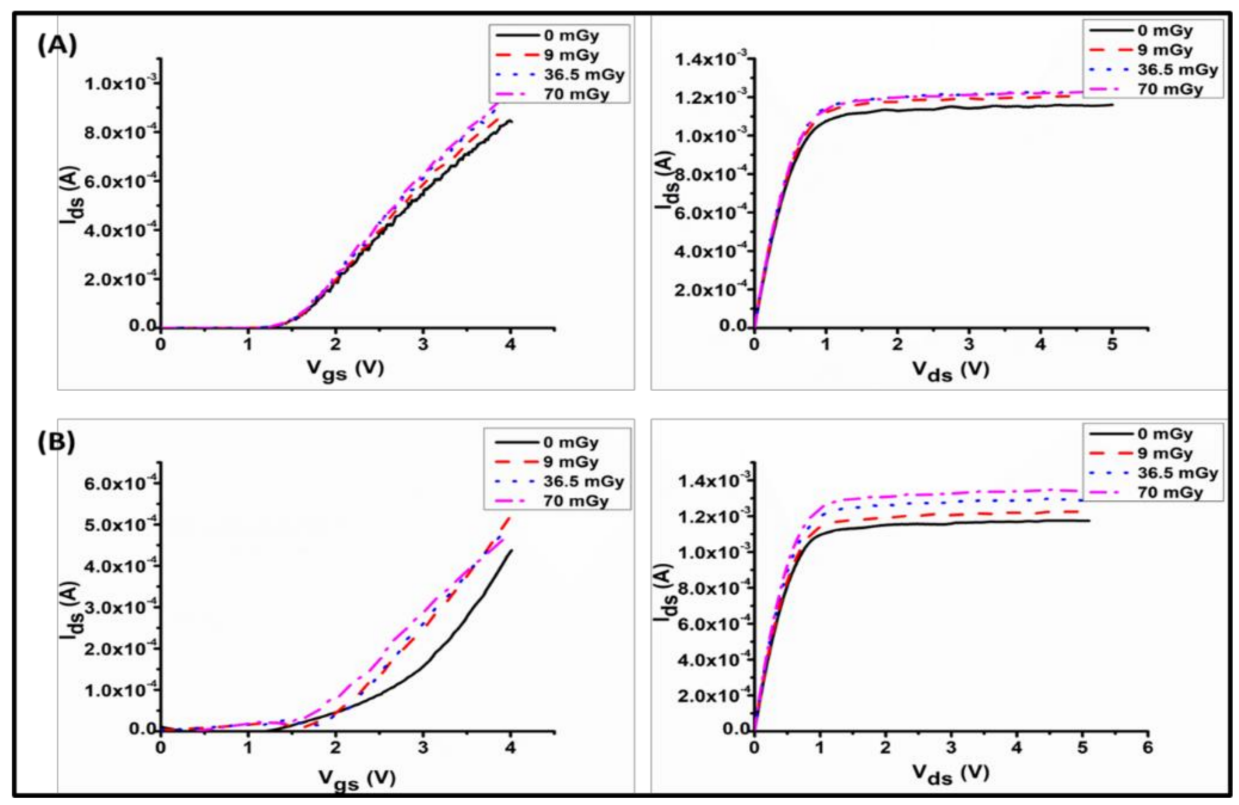

Figure 4. (A) Linear and saturation regime for the thin film and (B) linear and saturation regime for the $1 \mathrm{~mm}$ disk $\mathrm{ZnO}-\mathrm{Pb}$, under low absorbed dose.

The $\mathrm{ZnO}-\mathrm{Pb}$ thin film showed an increment in optical density up to the current level, less than $1.2 \times 10^{-3}$ A under absorbed dose $70 \mathrm{mGy}$, whereas thicker films $1 \mathrm{~mm}$ $\mathrm{ZnO}-\mathrm{Pb}$ sustained higher level of current $1.4 \times 10^{-3} \mathrm{~A}$ with a standard error varied from $3.4 \times 10^{-4}$ A for thin film to $8.546 \times 10^{-4} \mathrm{~A}$ for $1 \mathrm{~mm}$ thickness under the same absorbed dose and revealed detectable changes in its electrical characteristics. This is due to the fact that the deterioration is more severe with greater dosage and thinner films [25]. The change in the current $\Delta \mathrm{I}$ for the thin film was found to be $85 \mu \mathrm{A}$; this amount increased for $1 \mathrm{~mm}$ thickness to reach $172 \mu \mathrm{A}$. Also, from the graphs, we can notice that the $1 \mathrm{~mm} \mathrm{ZnO-Pb}$ disk responded to radiation more than the thin film because of the presence of $\mathrm{Pb}$, which has a high $Z_{\text {eff }}$ under low radiation dose, which interacts with radiation through the photoelectric effect and produces more photons, leading to increase in the current [26]. The current and voltage sensitivity values of TF and $1 \mathrm{~mm} \mathrm{ZnO-Pb}$ were calculated by plotting (I-Dose value) and (V-Dose value) curves, as mentioned in Figure 5. The voltage of the system was found to be decreased by increasing the absorbed dose from $3.13 \mathrm{~V}$ to $2.90 \mathrm{~V}$, within standard error $\pm 0.0118 \mathrm{~V}$ for the thin film and from $3.57 \mathrm{~V}$ to $3.06 \mathrm{~V} \pm 0.03 \mathrm{~V}$ for the $1 \mathrm{~mm}$ disk type. The linearity of the sensors was shown to be $94.5 \%$ for the thin film and $96.5 \%$ for the $1 \mathrm{~mm} \mathrm{ZnO}-\mathrm{Pb}$. In addition, small thicknesses are more sensitive to low radiation doses 
than high radiation dose [27]. The threshold voltage of the $\mathrm{ZnO}-\mathrm{Pb}$ samples was calculated by using Equation (1); it shows that for all samples, the threshold voltage rose by increasing the absorbed dose value and increasing the thickness of the samples (Figure 6). According to the graphs, increase in the thickness of $\mathrm{ZnO}-\mathrm{Pb}$ from several $\mu \mathrm{m}$ to $1 \mathrm{~mm}$ leads to a noticeable magnification in the $\Delta \mathrm{V}_{\mathrm{TH}}$ from 0.06 to $0.1 \mathrm{~V}$ for the thin film, and from 0.21 to $0.45 \mathrm{~V}$ for the $1 \mathrm{~mm}$ disk. Furthermore, as the sample thickness rises, so does the sensitivity of the dosimeter from $1.42 \mathrm{mV} / \mathrm{mGy}$ for the thin film to $6.42 \mathrm{mV} / \mathrm{mGy}$ for the $1 \mathrm{~mm}$ disk under radiation dose $70 \mathrm{mGy}$. Because the thick gate allows for more effective separation of electron-hole pairs produced within the oxide, the sensitivity will improve [28]. The sensitivity of the samples was measured using Equation (6); the sensitivity of the samples decreased on increasing the dose and increased with a rise in thickness of the devices. The characteristic results of the $\mathrm{ZnO}-\mathrm{Pb}$ thin film and disk type are tabulated in Table 2. One feature of the EGFET sensor that is observed with every detector is the inherent reduction in sensitivity with increased absorbed dose. This is thought to be produced by changes in the effective electric field supplied to the EGFET during irradiation, which results in a buildup of holes at the gate oxide contact [29].

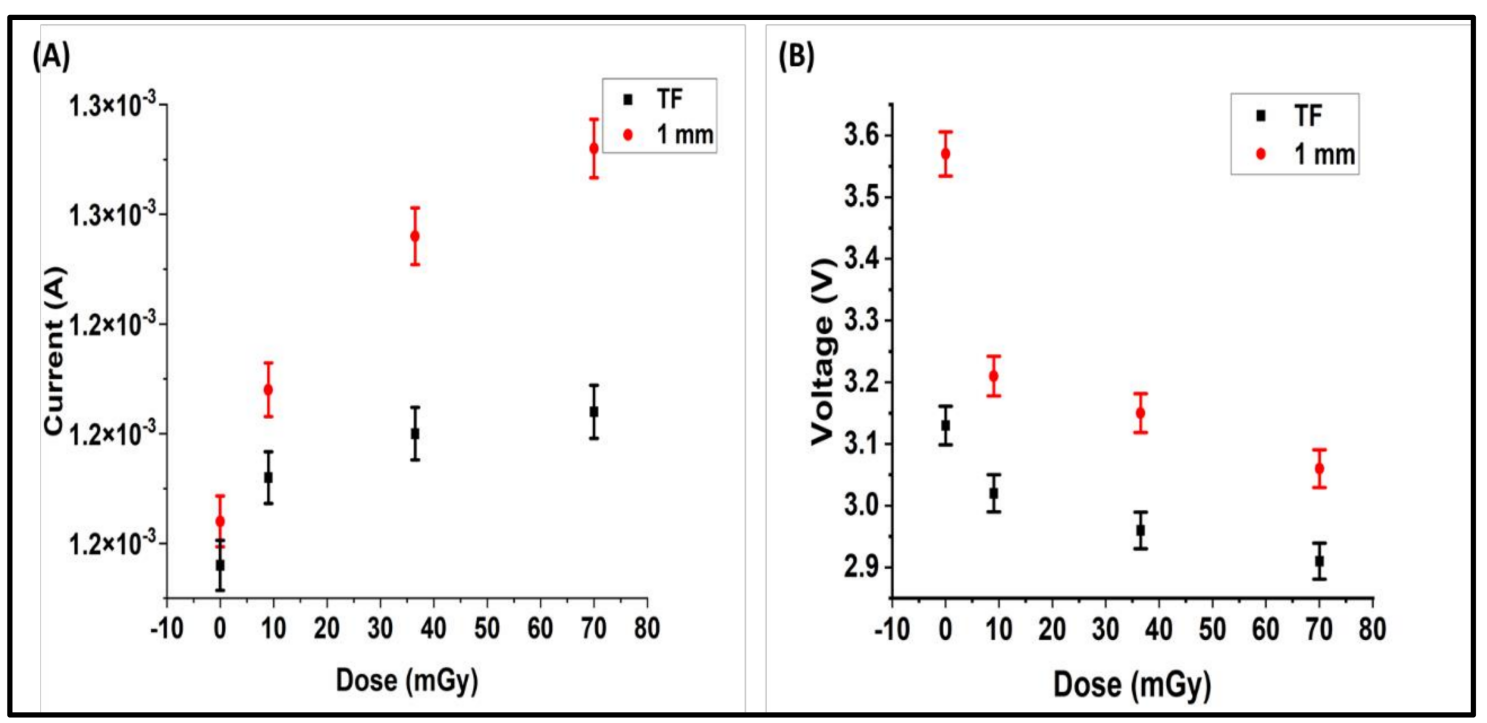

Figure 5. (A) Voltage vs. dose and (B) current vs. dose for both the thin film and the disk $\mathrm{ZnO}-\mathrm{Pb}$.

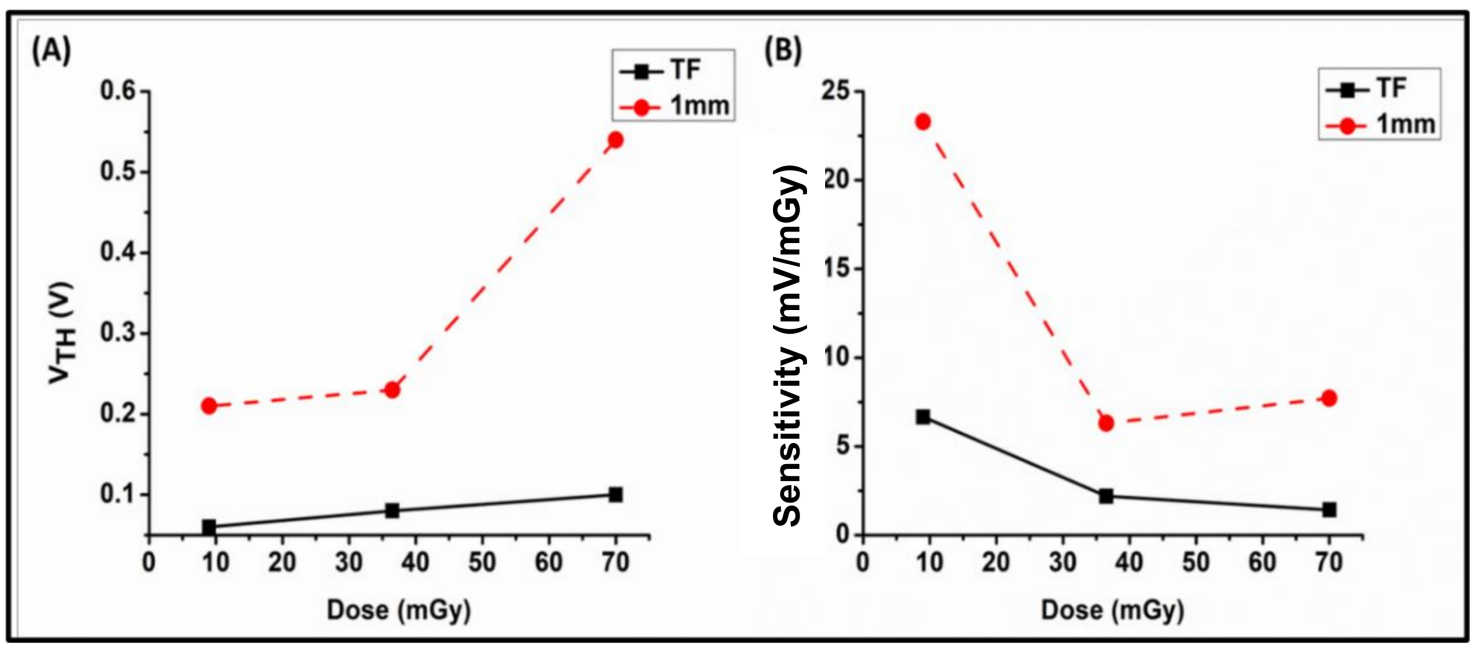

Figure 6. (A) Threshold voltage vs. dose and (B) sensitivity vs. dose for the $\mathrm{ZnO}-\mathrm{Pb}$ thin film and disks irradiated with the low dose. 
Table 2. Radiation sensing characteristics of $\mathrm{ZnO}-\mathrm{Pb}$ under low radiation doses and various thicknesses.

\begin{tabular}{|c|c|c|c|c|c|}
\hline \multirow{2}{*}{ Sample } & \multirow{2}{*}{$\begin{array}{l}\text { Absorbed Dose } \\
\text { (mGy) }\end{array}$} & \multirow{2}{*}{ Linearity \% } & \multirow{2}{*}{$\begin{array}{l}\text { Threshold Voltage } \\
\text { (mV) }\end{array}$} & \multicolumn{2}{|c|}{ Sensitivity } \\
\hline & & & & (mV/mGy) & $(\mu \mathrm{A} / \mathrm{mGy})$ \\
\hline \multirow{3}{*}{ TF $\mathrm{ZnO}-\mathrm{Pb}$} & 9 & \multirow{3}{*}{94.5} & 60 & 6.66 & \multirow{3}{*}{1.05} \\
\hline & 36.5 & & 80 & 2.19 & \\
\hline & 70 & & 100 & 1.42 & \\
\hline \multirow{3}{*}{$1 \mathrm{~mm}$ disk $\mathrm{ZnO}-\mathrm{Pb}$} & 9 & \multirow{3}{*}{96.5} & 210 & 23.3 & \multirow{3}{*}{2.28} \\
\hline & 36.5 & & 230 & 6.30 & \\
\hline & 70 & & 540 & 7.71 & \\
\hline
\end{tabular}

Current-voltage curves were plotted as shown in Figure 7A,B. The figures describe the radiation sensing characteristics of the $\mathrm{ZnO}-\mathrm{Pb}$ thin film and the $1 \mathrm{~mm}$ disk type under high absorbed doses (1, 5, and 10 Gy). These curves reflect a higher current value, compared to the same previous dosimeters exposed to low radiation doses. Moreover, the current value increased more in the sample $1 \mathrm{~mm} \mathrm{ZnO}-\mathrm{Pb}$ disk type than in the thin film. This is because ionizing radiation produces structural flaws (called color centers), which cause their density to vary as X-ray exposure increases [30]. High-energy radiations alter the physical characteristics of the materials through which they pass. The existence of oxygen vacancies influences the reactivity of oxide materials [31]. Moreover, the current value increased more in the sample $1 \mathrm{~mm} \mathrm{ZnO-Pb}$ disk type than that in the thin film $-\Delta \mathrm{I}$ for the thin film $=73 \mu \mathrm{A}$ and $1 \mathrm{~mm}=189 \mu \mathrm{A}$. Oxygen vacancies are present naturally in all oxides as Shottky or Frenkel faults, and their density can be raised or decreased in a variety of methods [32]. In the former scenario, the vacancy relates to two electrons. Increasing the radiation dose leads to rise in the defects.

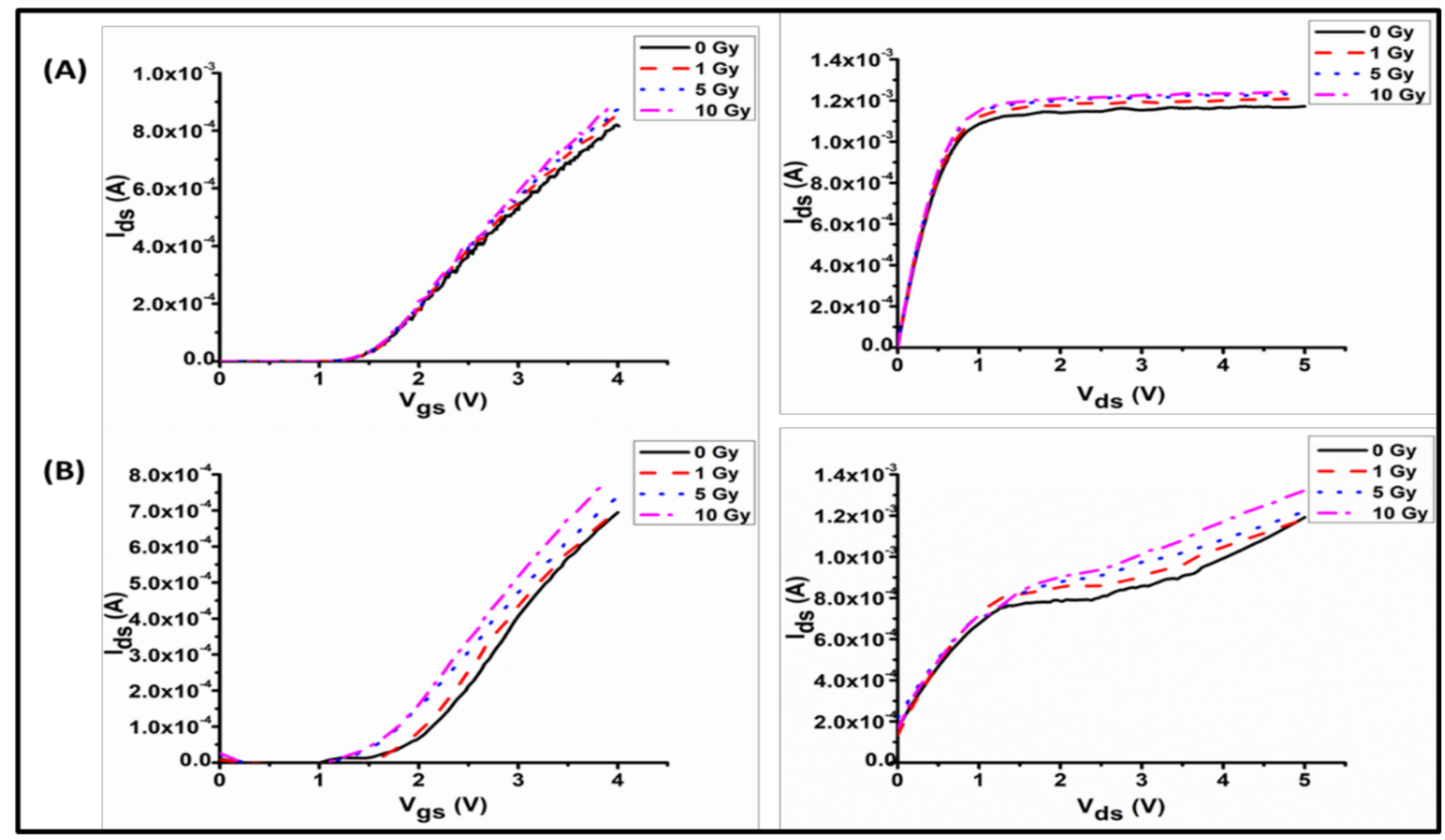

Figure 7. (A) Linear and saturation regime for the thin film and (B) linear and saturation regime for the $1 \mathrm{~mm}$ disk $\mathrm{ZnO}-\mathrm{Pb}$, under high absorbed dose.

From the above curves, the slopes of the ( $\mathrm{I}_{\mathrm{ds}}$-Dose value) and ( $\mathrm{V}_{\mathrm{gs}}$-Dose value) were used to calculate the present sensitivity and linearity of the detector to radiation (Figure 8): 
$5.80 \mu \mathrm{A} / \mathrm{Gy} \pm 0.545 \mu \mathrm{A}, 90.4 \%$ for the thin film and $21.5 \mu \mathrm{A} / \mathrm{Gy} \pm 0.14 \mu \mathrm{A}, 96.8 \%$ for $1 \mathrm{~mm} \mathrm{ZnO-Pb}$, for saturation and linear regimes, respectively. Also, the current rose on increasing the dose in the saturation regime, while the voltage decreases with a rise in the dose in the linear regime from $3.22 \mathrm{~V}$ to $2.94 \mathrm{~V} \pm 0.028 \mathrm{~V}$ for the thin film and from $3.28 \mathrm{~V}$ to $3.04 \mathrm{~V} \pm 0.02 \mathrm{~V}$ for the $1 \mathrm{~mm}$ thickness one. The threshold voltage of the samples shows that for all samples, the threshold voltage increased on increasing the absorbed dose value and increasing the thickness of the samples. Because the possibility of particle ionization by photoelectric effect is considerably greater than that by Compton's effect, a greater number of positive trap charge is created during low dose X-ray irradiation than during high dose X-ray irradiation, which obviously impacts the variety of values in the predominance of Compton interaction, as in this case [26].

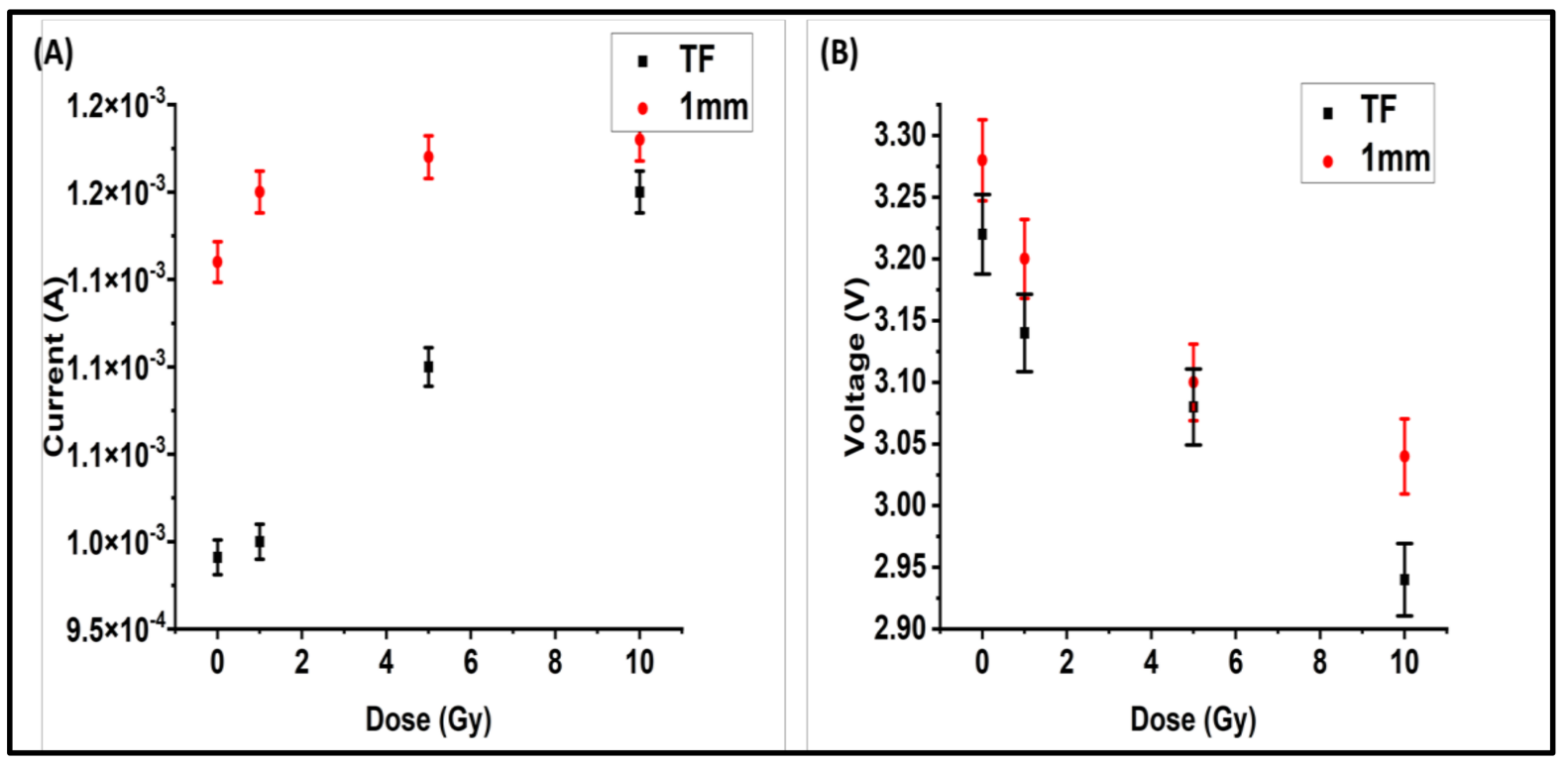

Figure 8. (A) Voltage vs. dose and (B) current vs. dose for the thin film and disk $\mathrm{ZnO}-\mathrm{Pb}$.

The sensitivity of the samples decreased on increasing the absorbed dose and increases on increasing the thickness of the samples. Figure 9 shows the threshold voltage and sensitivity plotting for all samples with absorbed dose value. We can notice that $1 \mathrm{~mm} \mathrm{ZnO-}$ $\mathrm{Pb}$ has higher $\Delta \mathrm{V}_{\mathrm{TH}}$ value and sensitivity than the other sample with lower thicknesses. The sensitivity of an MOS sensor is greatly dependent on the thickness of gate oxide ( $\left.T_{\mathrm{OX}}\right)$. The oxide functions as an ionization chamber, where $\mathrm{T}_{\mathrm{OX}}$ defines the ionization volume. In addition, as the thickness increases, the capacity of the oxide $\left(\mathrm{C}_{\mathrm{OX}}\right)$ decreases, so that at the same trapped load, the variation in the gate voltage is higher. The sensitivity of MOS dosimeters increases on the one hand with increasing ionization volume, and on the other with decreasing oxide capacity, then increases in $\mathrm{T}_{\mathrm{OX}}$, twice leading to increases in sensitivity. Therefore, the sensitivity has a dependence approximately proportional to $\mathrm{T}_{\mathrm{OX}}$ [33]. On the other hand, increasing the absorbed dose up to $10 \mathrm{~Gy}$ led to a drop in the sensitivity value for all the samples. This reduction in sensitivity with the applied dose is generated by changes in the functional electric field delivered to the EGFET throughout irradiations, which produces an accumulation of holes just at the oxide gate interface [34]. Table 3 summarizes the results of irradiation to a high X-ray dose. 


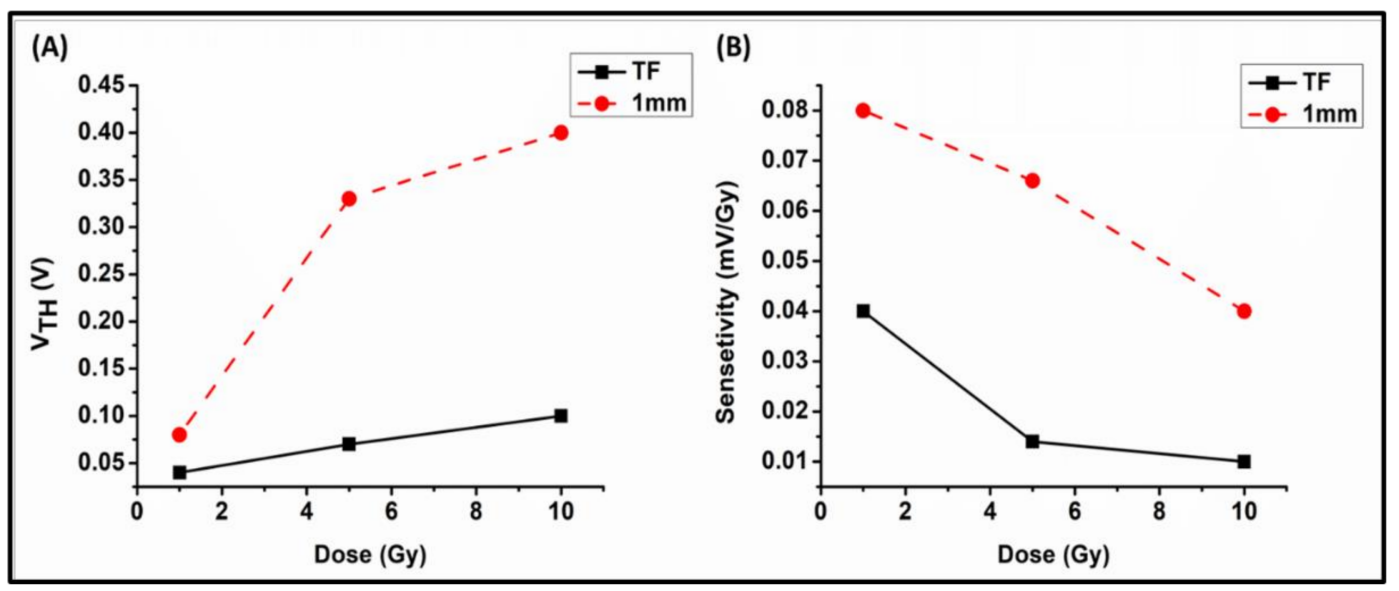

Figure 9. (A) Threshold voltage vs. dose and (B) sensitivity vs. dose for the $\mathrm{ZnO}-\mathrm{Pb}$ thin film and the disk irradiated with high dose.

Table 3. Radiation sensing characteristics of $\mathrm{ZnO}-\mathrm{Pb}$ under high radiation doses and various thicknesses.

\begin{tabular}{|c|c|c|c|c|c|}
\hline \multirow{2}{*}{ Sample } & \multirow{2}{*}{$\begin{array}{l}\text { Absorbed Dose } \\
\text { (Gy) }\end{array}$} & \multirow{2}{*}{ Linearity (\%) } & \multirow{2}{*}{$\begin{array}{c}\text { Threshold Voltage } \\
(\mathrm{mV})\end{array}$} & \multicolumn{2}{|c|}{ Sensitivity } \\
\hline & & & & (mV/Gy) & $(\mu \mathrm{A} / \mathrm{Gy})$ \\
\hline \multirow{3}{*}{ TF $\mathrm{ZnO}-\mathrm{Pb}$} & 1 & \multirow{3}{*}{90.4} & 0.04 & 0.04 & \multirow{3}{*}{5.80} \\
\hline & 5 & & 0.07 & 0.014 & \\
\hline & 10 & & 0.1 & 0.01 & \\
\hline \multirow{3}{*}{$1 \mathrm{~mm}$ disk $\mathrm{ZnO}-\mathrm{Pb}$} & 1 & \multirow{3}{*}{96.8} & 0.08 & 0.08 & \multirow{3}{*}{21.5} \\
\hline & 5 & & 0.33 & 0.066 & \\
\hline & 10 & & 0.4 & 0.04 & \\
\hline
\end{tabular}

\section{Conclusions}

Designing a measuring system utilizing the EGFET has clear advantages because of the low cost of production. The thin film and disk type extended gate was fabricated using CBD technique. The $\mathrm{X}$-ray response of the examined samples was measured by varying the threshold voltage and measuring the continuous drain current. According to the findings, EGFETs exhibit high linearity in the threshold voltage shift with radiation dosage; however, they are less sensitive to X-ray within the absorbed dose range of 1-10 Gy, as compared to their effective implementation for detection of low absorbed doses. Furthermore, due to the dominance of the photoelectric effect in this range of energies, EGFETs respond well at low energies $(100 \mathrm{keV})$. The greater photoelectric cross-section for metal than for metal oxide means that secondary electrons produced in the metal will cross into the metal oxide and contribute to the absorbed dose. To summarize, the rising dominance of photoelectric absorption and dose enhancement, as the incident absorbed dose between 9 mGy to $70 \mathrm{mGy}$, results in an increase in sensor sensitivity. According to the findings, these EGFETs may provide an acceptable response at considerably lower absorbed doses, allowing for their effective implementation in detecting low doses of several $\mathrm{mGy}$ utilized in diagnostic and therapeutic radiology.

Author Contributions: Conceptualization, N.M.A. and K.H.I.; methodology, N.M.A.; software, A.S.; validation, M.K.M.A., H.A. and O.A.A.; formal analysis, A.M.A.A.; investigation, A.M.A.A.; resources, H.A., O.A.A.; data curation, N.A.K. and K.H.I.; writing-original draft preparation, A.M.A.A.; writing-review and editing, N.M.A., H.A., O.A.A., K.H.I. and A.S.; visualization, N.A.K.; supervision, N.M.A. and N.A.K.; project administration, M.K.M.A., O.A.A., H.A., K.H.I. and A.S.; funding acquisition, M.K.M.A., H.A. and O.A.A. All authors have read and agreed to the published version of the manuscript. 
Funding: The authors extend their appreciation to the Deanship of Scientific Research at Imam Mohammad Ibn Saud Islamic University for funding this work through Research Group No. RG-21-09-52.

Institutional Review Board Statement: Not applicable.

Informed Consent Statement: Not applicable.

Acknowledgments: The authors are thankful to the Deanship of Scientific Research at Imam Mohammad Ibn Saud Islamic University for funding this work. The authors extend their appreciation to School of Physics, Universiti Sains Malaysia for the facilities and the technical support. The authors gratefully acknowledge Ahmed Alsadig (University of Trieste) for his kind assistance throughout this work.

Conflicts of Interest: The authors declare no conflict of interest.

\section{References}

1. Arshak, K.; Korostynska, O. Response of metal oxide thin film structures to radiation. Mater. Sci. Eng. B 2006, 133, 1-7. [CrossRef]

2. Thomson, I.; Thomas, R.; Berndt, L. Radiation dosimetry with MOS sensors. Radiat. Prot. Dosim. 1983, 6, 121-124. [CrossRef]

3. Yin, L.-T.; Chou, J.-C.; Chung, W.-Y.; Sun, T.-P.; Hsiung, S.-K. Study of indium tin oxide thin film for separative extended gate ISFET. Mater. Chem. Phys. 2001, 70, 12-16. [CrossRef]

4. Ahmed, N.M.; Kabaa, E.A.; Jaafar, M.S.; Omar, A.F. Characteristics of extended-gate field-effect transistor (EGFET) based on porous n-type (111) silicon for use in $\mathrm{pH}$ sensors. J. Electron. Mater. 2017, 46, 5804-5813. [CrossRef]

5. Ristic, G.; Golubovic, S.; Pejovic, M. pMOS dosimeter with two-layer gate oxide operated at zero and negative bias. Electron. Lett. 1994, 30, 295-296. [CrossRef]

6. Ristić, G.; Jakšić, A.; Pejović, M. pMOS dosimetric transistors with two-layer gate oxide. Sens. Actuators A Phys. 1997, 63, 129-134. [CrossRef]

7. O'Connell, B.; Conneely, C.; McCarthy, C.; Doyle, J.; Lane, W.; Adams, L. Electrical performance and radiation sensitivity of stacked PMOS dosimeters under bulkbias control. IEEE Trans. Nucl. Sci. 1998, 45, 2689-2694. [CrossRef]

8. Sarrabayrouse, G.; Buchdahl, D.; Polischuk, V.; Siskos, S. Stacked-MOS ionizing radiation dosimeters: Potentials and limitations. Radiat. Phys. Chem. 2004, 71, 737-739. [CrossRef]

9. Sarrabayrouse, G.; Gessinn, F. Thick oxide MOS transistors for ionizing radiation dose measurement. Radioprotection 1994, 29, 557-572. [CrossRef]

10. Vettese, F.; Donichak, C.; Bourgeault, P.; Sarrabayrouse, G. Assessment of a new p-MOSFET usable as a doserate insensitive gamma dose sensor. IEEE Trans. Nucl. Sci. 1996, 43, 991-996. [CrossRef]

11. Pejovic, M.M. P-channel MOSFET as a sensor and dosimeter of ionizing radiation. Facta Univ. Ser. Electron. Energetics 2016, 29, 509-541. [CrossRef]

12. Sze, S. Semiconductor device development in the 1970's and 1980's-A perspective. Proc. IEEE 1981, 69, 1121-1131. [CrossRef]

13. Gordillo, G.; Calderon, C. Properties of $\mathrm{ZnO}$ thin films prepared by reactive evaporation. Sol. Energy Mater. Sol. Cells 2001, 69, 251-260. [CrossRef]

14. Baydogan, N.; Ozdemir, O.; Cimenoglu, H. The improvement in the electrical properties of nanospherical ZnO: Al thin film exposed to irradiation using a Co-60 radioisotope. Radiat. Phys. Chem. 2013, 89, 20-27. [CrossRef]

15. Özgür, Ü.; Alivov, Y.I.; Liu, C.; Teke, A.; Reshchikov, M.A.; Dogan, S.; Avrutin, V.; Cho, S.-J.; Morkoc, H. A comprehensive review of $\mathrm{ZnO}$ materials and devices. J. Appl. Phys. 2005, 98, 11. [CrossRef]

16. Kannadasan, N.; Shanmugam, N.; Cholan, S.; Sathishkumar, K.; Viruthagiri, G.; Poonguzhali, R. Optical and electrochemical characteristics of $\mathrm{Pb}$ ions doped $\mathrm{ZnO}$ nanocrystals. Curr. Appl. Phys. 2014, 14, 1760-1766. [CrossRef]

17. Kannadasan, N.; Shanmugam, N.; Sathishkumar, K.; Cholan, S.; Ponnguzhali, R.; Viruthagiri, G. Optical behavior and sensor activity of Pb ions incorporated $\mathrm{ZnO}$ nanocrystals. Spectrochim. Acta Part A Mol. Biomol. Spectrosc. 2015, 143, 179-186. [CrossRef] [PubMed]

18. Ali, A.M.A.; Ahmed, N.M.; Kabir, N.A.; Almessiere, M.A. Multilayer ZnO/Pb/G thin film based extended gate field effect transistor for low dose gamma irradiation detection. Nucl. Instrum. Methods Phys. Res. Sect. A Accel. Spectrometers Detect. Assoc. Equip. 2021, 987, 164833. [CrossRef]

19. Khan, F.M.; Gibbons, J.P. Khan's the Physics of Radiation Therapy; Lippincott Williams \& Wilkins: Philadelphia, PA, USA, 2014.

20. Korostynska, O.; Hickey, G.; Forde, E. Ozone and gamma radiation sensing properties of $\operatorname{In}_{2} \mathrm{O}_{3}$ : $\mathrm{ZnO}_{\text {: }} \mathrm{SnO} 2$ thin films. Microsyst. Technol. 2008, 14, 557-566. [CrossRef]

21. Ali, A.M.A.; Ahmed, N.M.; Kabir, N.A.; Mohammad, S.M. Investigation on the characteristics of $\mathrm{ZnO}$ and $\mathrm{ZnO}-\mathrm{Pb}$ structure for gamma radiation detection. J. Phys. Conf. Ser. 2020, 1535, 012028.

22. Taherniya, A.; Raoufi, D. Thickness dependence of structural, optical and morphological properties of sol-gel derived TiO ${ }_{2}$ thin film. Mater. Res. Express 2018, 6, 016417. [CrossRef]

23. Arshak, K.; Corcoran, J.; Korostynska, O. Gamma radiation sensing properties of $\mathrm{TiO}_{2}, \mathrm{ZnO}, \mathrm{CuO}$ and CdO thick film pn-junctions. Sens. Actuators A Phys. 2005, 123, 194-198. [CrossRef] 
24. El-Mallawany, R.; Abousehly, A.; El-Rahamani, A.A.; Yousef, E. Radiation effect on the ultrasonic attenuation and internal friction of tellurite glasses. Mater. Chem. Phys. 1998, 52, 161-165. [CrossRef]

25. Arshak, K.; Korostynska, O.; Harriss, J. /spl gamma/-radiation dosimetry using screen printed nickel oxide thick films. In Proceedings of the 23rd International Conference on Microelectronics, Nis, Yugoslavia, 12-15 May 2002; IEEE: Piscataway, NJ, USA, 2002.

26. Pejović, M.; Ciraj-Bjelac, O.; Kovačević, M.; Rajović, Z.; Ilić, G. Sensitivity of P-channel MOSFET to X-and gamma-ray irradiation. Int. J. Photoenergy 2013, 2013, 158403. [CrossRef]

27. Pejović, M.M.; Pejović, M.M.; Jakšić, A.B. Radiation-sensitive field effect transistor response to gamma-ray irradiation. Nucl. Technol. Radiat. Prot. 2011, 26, 25-31. [CrossRef]

28. Asensio, L.; Carvajal, M.A.; Lopez-Villanueva, J.A.; Vilches, M.; Lallena, A.M.; Palma, A.J. Evaluation of a low-cost commercial mosfet as radiation dosimeter. Sens. Actuators A Phys. 2006, 125, 288-295. [CrossRef]

29. Lavallée, M.C.; Gingras, L.; Beaulieu, L. Energy and integrated dose dependence of MOSFET dosimeter sensitivity for irradiation energies between and. Med. Phys. 2006, 33, 3683-3689. [CrossRef]

30. Zhu, R.-Y. Radiation damage in scintillating crystals. Nucl. Instrum. Methods Phys. Res. Sect. A Accel. Spectrometers Detect. Assoc. Equip. 1998, 413, 297-311. [CrossRef]

31. Pacchioni, G.; Pescarmona, P. Structure and stability of oxygen vacancies on sub-surface, terraces, and low-coordinated surface sites of MgO: An ab initio study. Surf. Sci. 1998, 412, 657-671. [CrossRef]

32. Pacchioni, G. AB initio Theory of Point Defects in $\mathrm{SiO}_{2}$. In Defects in $\mathrm{SiO}_{2}$ and Related Dielectrics: Science and Technology; Springer: Berlin/Heidelberg, Germany, 2000; pp. 161-195.

33. Holmes-Siedle, A.; Ravotti, F.; Glaser, M. The dosimetric performance of RADFETs in radiation test beams. In Proceedings of the 2007 IEEE Radiation Effects Data Workshop, Honolulu, HI, USA, 23-27 July 2007; IEEE: Piscataway, NJ, USA, 2007.

34. Dozier, C.; Fleetwood, D.M.; Brown, D.B.; Winokur, P.S. An evaluation of low-energy X-ray and cobalt-60 irradiations of MOS transistors. IEEE Trans. Nucl. Sci. 1987, 34, 1535-1539. [CrossRef] 